\title{
Article \\ Determinants of Exercise Capacity Following ST-Elevation Myocardial Infarction (STEMI)
}

\author{
Harry Klimis ${ }^{1,2}$, Aaisha Ferkh ${ }^{1,2}$, Paula Brown ${ }^{2}$, Robert Zecchin ${ }^{2}\left(\right.$, Mikhail Altman ${ }^{1,2}$ (D) \\ and Liza Thomas $1,2,3, *$ \\ 1 Faculty of Medicine and Health, The University of Sydney, Camperdown, Sydney, NSW 2006, Australia; \\ harry.klimis@sydney.edu.au (H.K.); aaisha_Ferkh@hotmail.com (A.F.); altmanmikhail@hotmail.com (M.A.) \\ 2 Department of Cardiology Westmead Hospital, Westmead, Sydney, NSW 2145, Australia; \\ paula.Brown@health.nsw.gov.au (P.B.); Robert.Zecchin@health.nsw.gov.au (R.Z.) \\ 3 South Western Sydney Clinical School, University of New South Wales, Liverpool, NSW 2170, Australia \\ * Correspondence: liza.thomas@sydney.edu.au
}

check for updates

Citation: Klimis, H.; Ferkh, A.; Brown, P.; Zecchin, R.; Altman, M.; Thomas, L. Determinants of Exercise Capacity Following ST-Elevation Myocardial Infarction (STEMI). J. Cardiovasc. Dev. Dis. 2021, 8, 140. https: / / doi.org/10.3390/ jcdd 8110140

Academic Editors: Kenya Kusunose and Roberto F. E. Pedretti

Received: 14 September 2021

Accepted: 27 October 2021

Published: 28 October 2021

Publisher's Note: MDPI stays neutral with regard to jurisdictional claims in published maps and institutional affiliations.

Copyright: (c) 2021 by the authors. Licensee MDPI, Basel, Switzerland. This article is an open access article distributed under the terms and conditions of the Creative Commons Attribution (CC BY) license (https:// creativecommons.org/licenses/by/ $4.0 /)$.

\begin{abstract}
Background: Abnormal left ventricular systolic and diastolic function and reduced exercise capacity are associated with worse prognosis following ST-elevation myocardial infarction (STEMI). However, evidence is lacking on the determinants of exercise capacity following STEMI. We sought to determine the impact of systolic and diastolic dysfunction on exercise capacity and outcomes following first-ever STEMI. Methods: In a retrospective analysis of 139 consecutive STEMI patients who had a transthoracic echocardiogram following STEMI and completed exercise treadmill testing, the primary outcome was to identify clinical and echocardiographic determinants of exercise capacity, and the secondary outcome was to identify determinants of major adverse cardiac events (MACEs). Results: Mean number of metabolic equivalents (METs > 8) was used as a cut-off. Age, female sex, anterior infarction, abnormal diastolic function, minimum left atrial indexed volume $\left(\mathrm{LAVI}_{\min }\right) \geq 18 \mathrm{~mL} / \mathrm{m}^{2}$, average $\mathrm{e}^{\prime}$, and $\mathrm{E} / \mathrm{e}^{\prime}$ were associated with $\mathrm{METs} \leq 8$, but not left ventricular ejection fraction (LVEF). On multivariate analysis, $\mathrm{LAVI}_{\min }(\mathrm{OR} 4.3,95 \% \mathrm{CI} 1.3-14.2 ; p=0.017$ ), anterior infarction (OR 2.6, 95\%CI 1.2-5.9; $p=0.022$ ), and abnormal diastolic function (OR 3.73, $95 \%$ CI 1.7-8.4; $p=0.001)$ were independent predictors of METs $\leq 8$. On Kaplan-Meier analysis, METs $\leq 8(p=0.01)$ and abnormal diastolic function $(p=0.04)$ were associated with MACEs (median follow-up 2.3 years). METs $\leq 8$ was an independent predictor of MACEs (HR 3.4, 95\%CI 1.2-9.8; $p=0.02$ ). Conclusions: Following first-ever STEMI, increased LAVI ${ }_{\min }$, anterior infarction, and abnormal diastolic function were independent predictors of reduced exercise capacity. Furthermore, reduced exercise capacity was an independent predictor of MACEs. These results highlight important prognostic and therapeutic implications related to abnormal diastolic function in STEMI patients that are distinct from those with LV systolic impairment.
\end{abstract}

Keywords: STEMI; myocardial infarction; diastolic function; systolic function; exercise capacity; metabolic equivalents; exercise stress test; echocardiography; left atrial volume

\section{Introduction}

Exercise capacity following acute ST-segment elevation myocardial infarction (STEMI) has been used as a surrogate marker and a predictor of poor outcomes [1-3]. Specifically, the role of monitored exercise as part of cardiac rehabilitation after acute myocardial infarction (AMI) has been shown to reduce cardiovascular mortality [4], and its importance is reflected in current guidelines [5]. However, the determinants of reduced exercise capacity following STEMI are not well established.

Although left ventricular ejection fraction (LVEF) is a well-established predictor of mortality after myocardial infarction, LVEF per se does not predict exercise capacity, as reported both in patients after myocardial infarction and in unselected patients [6,7]. Only a few studies have demonstrated that diastolic dysfunction may be a more important 
determinant of exercise capacity as compared to systolic function following myocardial infarction $[6,8]$. However, there are sparse data on the impact of diastolic function early after STEMI on exercise capacity. Current evidence on exercise capacity includes largely a heterogeneous postinfarct group that does not focus specifically on acute STEMI patients $[1,6,8,9]$. These studies often include patients with remote myocardial infarction [6], do not comprise a contemporary cohort [9], and have relatively small sample sizes [1,6,9].

Exercise treadmill testing (ETT) and estimation of metabolic equivalents (METs) are used in cardiac rehabilitation for STEMI patients. METs achieved at ETT have been demonstrated to be an independent predictor of cardiac morbidity and mortality in a variety of unselected patients $[2,3,10,11]$ and as a strong predictor of long-term mortality in unselected men referred for ETT [12].

Our aim was to examine the clinical and echocardiographic determinants of exercise capacity defined by METs achieved by ETT, following first-ever STEMI. We additionally sought to determine the prognostic value of METs achieved for a composite of cardiovascular morbidity and mortality. We hypothesised that measures of abnormal diastolic function may be more significant determinants of reduced exercise capacity as compared with systolic function.

\section{Materials and Methods}

\subsection{Study Design}

This was a retrospective cohort study of consecutive patients with first-ever STEMI, presenting between November 2015 and 2017 to Westmead Hospital, Sydney, Australia, a tertiary referral centre.

\subsection{Study Participants}

Patients were included if fulfilling prespecified eligibility criteria based on having received standard of care for STEMI patients at our centre. Eligible patients were aged $\geq 18$ years, admitted with first-ever STEMI, had a transthoracic echocardiogram (TTE) performed following the incident event, and subsequently attended cardiac rehabilitation at our centre. All included patients had exercise capacity assessed by an ETT. Patients in atrial fibrillation at the time of TTE, with greater than moderate valvular regurgitation, with severe mitral annular calcification, or with previous valve replacement/repair were excluded from the analysis as diastolic function in these groups cannot be accurately graded [13].

\subsection{Study Objectives}

The primary objective was to identify clinical and systolic and diastolic echocardiographic parameters that were determinants of exercise capacity at ETT during cardiac rehabilitation. The secondary objective was to determine the prognostic significance of reduced exercise capacity at ETT with major adverse cardiac events (MACEs), defined as the composite endpoint of cardiovascular hospitalisation for recurrent angina, acute coronary syndrome (ACS), heart failure, arrhythmias, and cardiovascular mortality (death related to cardiovascular causes or sudden death).

\subsection{Data Collection}

Prespecified demographic and clinical data were retrospectively collected from electronic medical records. Data were extracted from New South Wales Health Information Exchange by the WSLHD Clinical Analytics and Performance Unit on 30 July 2019, and outcomes were collected until 29 March 2019 (follow-up duration from hospital STEMI presentation: range 1.3-3.4 years; mean 2.3 years). Prespecified echocardiographic parameters were measured from a comprehensive TTE performed following index presentation with STEMI. All TTEs were reanalysed for this study by an investigator blinded to patient, clinical, and ETT details and outcomes. Overall diastolic function was graded and individual parameters of diastolic function (transmitral $\mathrm{E}$ and A velocity, E/A ratio, deceleration time, 
tissue Doppler e' velocity, E/e', and left atrial volumes) were evaluated. Diastolic grade was determined according to 2016 guidelines [13] by two independent cardiologists (LT and MA) blinded to patient details and grouped for analysis into abnormal and normal diastolic function (i.e., based on a combination of individual echocardiographic parameters as defined by 2016 guidelines). Discrepancies in diastolic grading between the two independent cardiologists were resolved by discussion. An average of three consecutive measurements was taken for Doppler assessment of transmitral flow velocity (E, E/A, and deceleration time) and tissue Doppler-derived septal and lateral annular early diastolic velocity (average e'). Simpson's biplane method was used to measure left ventricular (LV) end-diastolic volume (EDV) and end-systolic volume (ESV) and estimate LVEF. Maximum and minimum left atrial volumes were measured from apical 4 and 2 chamber views by Simpson's biplane method and indexed to body surface area.

Safety of early ETT in STEMI patients has been previously reported by our cardiac rehabilitation program [14]. Exercise stress tests were performed using a General Electric Stress Analyser and treadmill Case Version 6.51 (GE Healthcare Technologies, Milwaukee, WI, USA). Exercise capacity was determined using METs (metabolic equivalents) achieved during maximal symptom and sign limited ETT performed after STEMI using either Bruce, modified Bruce, or modified Naughton protocols. Criteria for test termination included maximum predicted heart rate achieved, systolic blood pressure $>220 \mathrm{mmHg}$, diastolic blood pressure $>110 \mathrm{mmHg}$, ischaemic ST-segment changes (at least $4 \mathrm{~mm}$ of ST-segment elevation or depression (horizontal or down-sloping) $80 \mathrm{~ms}$ after the J point), chronotropic incompetence, new left or right bundle branch block, tachyarrhythmias, heart block, or patient request [14].

METs were dichotomised according to the mean METs achieved as $\leq 8$ and $>8$ (mean METs achieved in the total study population: 7.8 (SD 3.1) METs). Age was categorised as $\leq 59$ years and $>59$ years based on the mean age of the group, and gender was categorised as male and female. Smoking status was divided into three groups: current smoker, former smoker, and never smoked. Left atrial indexed volume was dichotomised based on cut-offs from expert consensus and previous studies: $\geq 34 \mathrm{~mL} / \mathrm{m}^{2}$ for maximum [15] and $\geq 18 \mathrm{~mL} / \mathrm{m}^{2}$ for minimum left atrial indexed volumes [16,17]. LVEF was dichotomised based on a normal value of $\geq 52 \%$ [15]. Tricuspid regurgitant jet velocity was dichotomised based on a value of $\geq 2.8 \mathrm{~m} / \mathrm{s}$ [13]. Territory of infarction was based on 12-lead electrocardiogram (ECG) criteria.

\subsection{Statistical Analysis}

SPSS Statistics version 24.0 for Windows (SPSS Inc. An IBM Company, Chicago, IL, USA) was used for analysis; $p$-values $\leq 0.05$ were considered statistically significant. Sample distributions of demographics and clinical characteristics at baseline were examined using descriptive statistics. Continuous and categorical variables were expressed as mean $\pm \mathrm{SD}$ and number (\%) respectively. For univariate analyses, two-sample $t$-tests for continuous variables or $\chi^{2}$ tests of independence for categorical variables were performed to determine associations between METs and clinical and echocardiographic factors. Clinical factors included age, gender, body mass index (BMI), waist circumference, STEMI territory (by ECG criteria), diabetes, smoking status, symptom onset to table time and TIMI III flow (thrombolysis in myocardial infarction), days until cardiac rehabilitation from STEMI, and serum creatinine. Echocardiographic parameters of diastolic function assessed included transmitral parameters (peak E velocity, E/A ratio, and deceleration time), mitral annular tissue Doppler parameters (average e' velocity and E/e' ratio), indexed left atrial volume (maximum and minimum), and peak tricuspid regurgitant velocity; overall diastolic function was graded as normal or abnormal as described in Section 2.4. LV systolic function was evaluated by LVEF. Variables found to have $p$-values $<0.05$ on univariate analyses were included in the multivariable logistic regression model for exercise capacity. Backward elimination was conducted to select the final predictive model for METs $\leq 8$. The criterion for the removal of the candidate predictor variables from the multivariable model 
was set at $p<0.10$. Cumulative incidence of MACEs was estimated by the Kaplan-Meier method and compared between groups by the log-rank test. For univariate analysis of MACEs, a Cox regression analysis was performed on the variables included in the final multivariable model for METs $\leq 8$, in addition to METs achieved. Variables found to have $p$-values $<0.05$ on univariate analyses were included in the multivariable Cox regression model for MACEs.

\subsection{Ethical Considerations}

This study was approved by the Western Sydney Local Health District (WSLHD) Human Research Ethics Committee (AU RED LNR/17/WMEAD/192) and conformed to the provisions of the Declaration of Helsinki. Data from this research were completely deidentified and reported only as combined totals.

\section{Results}

\subsection{Demographics}

One hundred thirty-nine consecutive eligible patients (November 2015-2017) were assessed. Table 1 shows the baseline clinical characteristics of the entire cohort. Mean age was 59.2 (SD 11.7) years (range 32-85 years), and 12/139 (8.6\%) were female. Mean time from STEMI to TTE was 3.2 (SD 6.1) days. Mean time from STEMI to ETT was 24.7 (SD 17.5) days, and mean number of METs achieved was 7.8 (SD 3.1) METs. All patients included were in sinus rhythm.

Table 1. Baseline clinical characteristics.

\begin{tabular}{|c|c|}
\hline Variable & Cohort $(n=139)$ \\
\hline Age; mean $\pm \mathrm{SD}$ (years) & $59.2 \pm 11.7$ \\
\hline Male; $n(\%)$ & $127(91.4 \%)$ \\
\hline $\mathrm{BMI} ;$ mean $\pm \mathrm{SD}\left(\mathrm{kg} / \mathrm{m}^{2}\right)$ & $27.7 \pm 4.7$ \\
\hline Waist circumference; mean \pm SD $(\mathrm{cm})$ & $99.2 \pm 11.5$ \\
\hline Current smokers; $n(\%)$ & $37(26.6 \%)$ \\
\hline Former smokers; $n(\%)$ & $29(20.9 \%)$ \\
\hline Never smoked; $n(\%)$ & $73(52.5 \%)$ \\
\hline Hypertension; $n(\%)$ & $63(45.3 \%)$ \\
\hline Hypercholesterolaemia; $n(\%)$ & $134(96.4 \%)$ \\
\hline Diabetes mellitus; $n(\%)$ & $36(25.9 \%)$ \\
\hline Family history of premature CAD; $n(\%)$ & $52(37.4 \%)$ \\
\hline Creatinine; mean $\pm \mathrm{SD}(\mu \mathrm{mol} / \mathrm{L})$ & $84.3 \pm 29.5$ \\
\hline Anterior infarction; $n(\%)$ & $72(51.8 \%)$ \\
\hline Inferior infarction; $n(\%)$ & $61(43.9 \%)$ \\
\hline Lateral infarction; $n(\%)$ & $6(4.3 \%)$ \\
\hline Normal diastolic function & $62(44.6 \%)$ \\
\hline Grade 1 diastolic dysfunction & $48(34.5 \%)$ \\
\hline Grade 2 diastolic dysfunction & $29(20.9 \%)$ \\
\hline Grade 3 diastolic dysfunction & $0(0 \%)$ \\
\hline Normal LV systolic function (LVEF * 52-72\%); $n(\%)$ & $67(48.2 \%)$ \\
\hline Mild LV systolic impairment (LVEF * 41-51\%); $n(\%)$ & $51(36.7 \%)$ \\
\hline Moderate LV systolic impairment (LVEF * 30-40\%); $n(\%)$ & $17(12.2 \%)$ \\
\hline Severe LV systolic impairment (LVEF * <30\%); $n(\%)$ & $4(2.9 \%)$ \\
\hline
\end{tabular}

SD, standard deviation; BMI, body mass index; CAD, coronary artery disease; LV, left ventricular * 2DE-derived LVEF as calculated by Simpson's biplane [18].

Just over half the patients had an anterior infarction $(72 / 139,51.8 \%)$. Most were treated with percutaneous coronary intervention (PCI) $(126 / 139,90.6 \%), 4 / 139$ (2.9\%) had coronary artery bypass grafting, and $9 / 139$ (6.5\%) received medical therapy only. Most received dual antiplatelet therapy $(133 / 139,95.7 \%), 4 / 139$ (2.9\%) received single antiplatelet therapy with anticoagulation, and 2/139 (1.4\%) received triple therapy (dual antiplatelet therapy and anticoagulation). Time from symptom onset to TIMI III flow was available for 107/139 (77.0\%) of patients and was 418.9 (SD 698.6) minutes. TIMI III flow was not achieved in 
$6 / 139(4.3 \%)$ of patients, and 26/139 (18.7\%) did not have symptom onset recorded. Time from symptom onset to table was recorded for 113/139 (81.3\%) patients with a mean of 381.2 (SD 675.8) minutes. Most were on appropriate secondary prevention medication at discharge-137/139 (98.6\%) were on statin therapy, 116/139 (83.5\%) were on beta blockers, and $94 / 139(67.6 \%)$ were on angiotensin-converting enzyme (ACE) inhibitors/angiotensin receptor blockers.

LVEF was calculated for all patients (Table 1); mean LVEF was 51.2\% (SD 9.8\%). Diastolic function was graded for all patients; $62 / 139(44.6 \%)$ had normal diastolic function, 48/139 (34.5\%) grade 1 diastolic dysfunction, 29/139 (20.9\%) had grade 2 diastolic dysfunction, and none had grade 3 diastolic dysfunction.

\subsection{Primary Outcome}

METs achieved had a significant inverse correlation with left atrial minimum indexed volume $\left(\mathrm{LAVI}_{\min }\right)(\beta-0.085,95 \% \mathrm{CI}-0.162$ to $-0.008 ; p=0.031)$, left atrial maximum indexed volume $\left(\mathrm{LAVI}_{\max }\right)(\beta-0.053,95 \% \mathrm{CI}-0.103$ to $-0.004 ; p=0.035)$, and $\mathrm{E} / \mathrm{e}^{\prime}$ $(\beta-0.383,95 \% \mathrm{CI}-0.527$ to $-0.239 ; p<0.001)$. METs achieved had a significant positive correlation with E velocity $(\beta 0.512,95 \% \mathrm{CI} 0.275$ to $0.749 ; p<0.001)$. There was no significant correlation with LVEF ( $\beta 0.015,95 \% \mathrm{CI}-0.040$ to $0.071 ; p=0.583$ ). Further analyses were performed to determine independent predictors of reduced exercise capacity (mean METs achieved as the binary cut-off (i.e., $\leq 8$ versus $>8 \mathrm{METs}$ )).

Individual parameters of diastolic function including transmitral $\mathrm{E}$ and $\mathrm{A}$ velocity, $\mathrm{E} / \mathrm{A}$ ratio, deceleration time, $\mathrm{e}^{\prime}$ velocities, $\mathrm{E} / \mathrm{e}^{\prime}$, and LA maximum and minimum volume were compared between groups based on METs achieved (Table 2). The number of METs achieved was significantly lower in patients with abnormal diastolic function compared to those with normal diastolic function (6.8 (SD 2.8) vs. 9.0 (SD 3.0) METs; $p<0.001$ ). Increasing age, presence of anterior infarction, abnormal diastolic function, and individual diastolic function variables (lower average $\mathrm{e}^{\prime}$ and higher $\mathrm{E} / \mathrm{e}^{\prime}$ ) were associated with METs $\leq 8$. Additionally, $\mathrm{LAVI}_{\min } \geq 18 \mathrm{~mL} / \mathrm{m}^{2}(p=0.01)$ was associated with METs $\leq 8$, but LAVI $I_{\max }>34 \mathrm{~mL} / \mathrm{m}^{2}(p=0.15)$ was not. LVEF $<52 \%$ was not associated with METs $\leq 8(p=0.15)$.

Table 2. Baseline variables of interest by METs achieved in a univariate logistic regression.

\begin{tabular}{|c|c|c|c|}
\hline & \multicolumn{2}{|c|}{ METs Achieved } & \multirow[t]{2}{*}{$p$-Value } \\
\hline & $\leq 8 \mathrm{METs}$ & $>8$ METs & \\
\hline Age > 59 years; $n(\%)$ & $51(55.4)$ & $12(25.5)$ & 0.001 \\
\hline Male; $n(\%)$ & $81(88.0)$ & $46(97.9)$ & 0.051 \\
\hline BMI $\left(\mathrm{kg} / \mathrm{m}^{2}\right) ;$ mean $(\mathrm{SD})$ & $27.3(5.1)$ & $28.4(4.0)$ & 0.221 \\
\hline Waist circumference (cm); mean (SD) & $98.7(11.9)$ & $100.1(10.8)$ & 0.510 \\
\hline Diabetes; $n(\%)$ & $27(29.3)$ & $9(19.1)$ & 0.194 \\
\hline Hypertension; $n(\%)$ & $45(48.9)$ & $18(38.3)$ & 0.237 \\
\hline Smoking status & & & 0.374 \\
\hline Never smoked; $n(\%)$ & $48(52.2)$ & $25(53.2)$ & \\
\hline Former smoker; $n(\%)$ & $22(23.9)$ & $7(14.9)$ & \\
\hline Current smoker; $n(\%)$ & $22(23.9)$ & $15(31.9)$ & \\
\hline Time from pain to table (min); mean (SD) & $420.5(733.0)$ & $309.3(558.0)$ & 0.084 \\
\hline Pain to TIMI III (min); mean (SD) & $468.4(757.3)$ & $346.1(565.3)$ & 0.382 \\
\hline Days until cardiac rehabilitation; mean (SD) & $22.3(12.9)$ & $29.4(23.7)$ & 0.347 \\
\hline Creatinine $(\mu \mathrm{mol} / \mathrm{L}) ;$ mean $(\mathrm{SD})$ & $84.0(33.9)$ & $84.8(18.4)$ & 0.246 \\
\hline Peak E (cm/s); mean (SD) & $70.7(18.7)$ & $70.4(13.6)$ & 0.845 \\
\hline Peak A (cm/s); mean (SD) & $76.0(20.2)$ & $69.0(18.3)$ & 0.068 \\
\hline $\mathrm{E} / \mathrm{A} ;$ mean $(\mathrm{SD})$ & $0.98(0.32)$ & $1.09(0.34)$ & 0.060 \\
\hline DT (ms); mean (SD) & $193.7(52.8)$ & $193.6(40.4)$ & 0.608 \\
\hline $\mathrm{e}^{\prime}$ septal $(\mathrm{cm} / \mathrm{s}) ;$ mean $(\mathrm{SD})$ & $5.8(1.6)$ & $7.1(1.9)$ & $<0.001$ \\
\hline $\mathrm{e}^{\prime}$ lateral $(\mathrm{cm} / \mathrm{s}) ;$ mean $(\mathrm{SD})$ & $7.4(2.6)$ & $9.2(2.6)$ & $<0.001$ \\
\hline Average $\mathrm{e}^{\prime}(\mathrm{cm} / \mathrm{s})$; mean (SD) & $6.6(2.0)$ & $8.1(2.0)$ & $<0.001$ \\
\hline
\end{tabular}


Table 2. Cont.

\begin{tabular}{|c|c|c|c|}
\hline & \multicolumn{2}{|c|}{ METs Achieved } & \multirow[t]{2}{*}{$p$-Value } \\
\hline & $\leq 8 \mathrm{METs}$ & $>8$ METs & \\
\hline E/e'; mean (SD) & $11.3(3.5)$ & $9.4(2.8)$ & 0.001 \\
\hline LA volume indexed (maximum) $>34 \mathrm{~mL} / \mathrm{m}^{2} ; n(\%)$ & $45(48.9)$ & $17(36.2)$ & 0.153 \\
\hline LA volume indexed (minimum) $\geq 18 \mathrm{~mL} / \mathrm{m}^{2} ; n(\%)$ & $25(27.2)$ & $4(8.5)$ & 0.009 \\
\hline LVEF $<52 \% ; n(\%)$ & $55(59.8)$ & $22(46.8)$ & 0.145 \\
\hline Peak TR vel > $2.8 \mathrm{~m} / \mathrm{s} ; n(\%)$ & $10(10.9)$ & $4(8.5)$ & 0.662 \\
\hline Diastolic dysfunction *; $n(\%)$ & $62(67.4)$ & $15(31.9)$ & $<0.001$ \\
\hline
\end{tabular}

BMI, body mass index; TIMI, thrombolysis in myocardial infarction (TIMI III refers to complete perfusion); DT, deceleration time; LA, left atrium; LVEF, left ventricular ejection fraction; TR, tricuspid regurgitation. * Grouped as absent or present.

Multivariate logistic regression (Table 3) was performed using age (dichotomised as mean of 59 years), anterior infarction, abnormal diastolic function, $\mathrm{LAVI}_{\min }$ (dichotomised based on upper limit of normal $\left.\geq 18 \mathrm{~mL} / \mathrm{m}^{2}\right)$, and average $\mathrm{E} / \mathrm{e}^{\prime}\left(\mathrm{e}^{\prime}\right.$ velocity was colinear with $\mathrm{E} / \mathrm{e}^{\prime}$ ratio and not included in the multivariate model). Sex was not included as $91.4 \%$ were male. $\mathrm{LAVI}_{\min }$ (OR $4.3,95 \% \mathrm{CI} 1.3-14.2 ; p=0.017$ ), anterior infarction (OR 2.6, 95\%CI 1.2-5.9; $p=0.022$ ), and abnormal diastolic function (OR 3.73, 95\%CI 1.7-8.4; $p=0.001$ ) were independent predictors of reduced exercise capacity.

Table 3. Multivariable logistic regression for METs $\leq$ 8: final model.

\begin{tabular}{cc}
\hline Variable & Odds Ratio (95\% Confidence Interval) \\
\hline Left atrial indexed volume (minimum) & OR 4.3 (1.3-14.2)* \\
Abnormal diastolic function & OR 3.7 $(1.7-8.4)^{* *}$ \\
Anterior infarction & OR 2.6 (1.2-5.9) \\
\hline${ }^{*} p<0.05 ; * *<0.01$. &
\end{tabular}

\subsection{Secondary Outcome}

The mean follow-up from TTE was 718 (SD 324) days, and there were 86 cardiac events including 2 deaths (both due to end-stage heart failure) in a total of 29 patients. The diagnoses of first MACE presentation are presented in Table 4. Survival analyses were performed using METs achieved and variables found significant in multivariable logistic regression presented in Table 3. On Kaplan-Meier analysis, METs $\leq 8$ was associated with MACEs (log-rank statistic $6.16 ; p=0.01$; Figure 1), as was presence of abnormal diastolic function (log-rank statistic 4.39; $p=0.04$; Figure 2). There was no association of $\mathrm{LAVI}_{\min }$ or anterior infarction with MACEs.

Table 4. First major adverse cardiac event diagnoses.

\begin{tabular}{ccc}
\hline Diagnosis & Frequency & $\boldsymbol{n = 1 3 9 ( \% )}$ \\
\hline Recurrent angina & 7 & 5.0 \\
Unstable angina & 5 & 3.6 \\
NSTEMI & 9 & 6.5 \\
STEMI & 1 & 0.7 \\
Heart failure & 4 & 2.9 \\
Arrhythmia & 3 & 2.2 \\
\hline
\end{tabular}

ACS, acute coronary syndrome; NSTEMI, non-ST-elevation myocardial infarction; STEMI, ST-elevation myocardial infarction. 


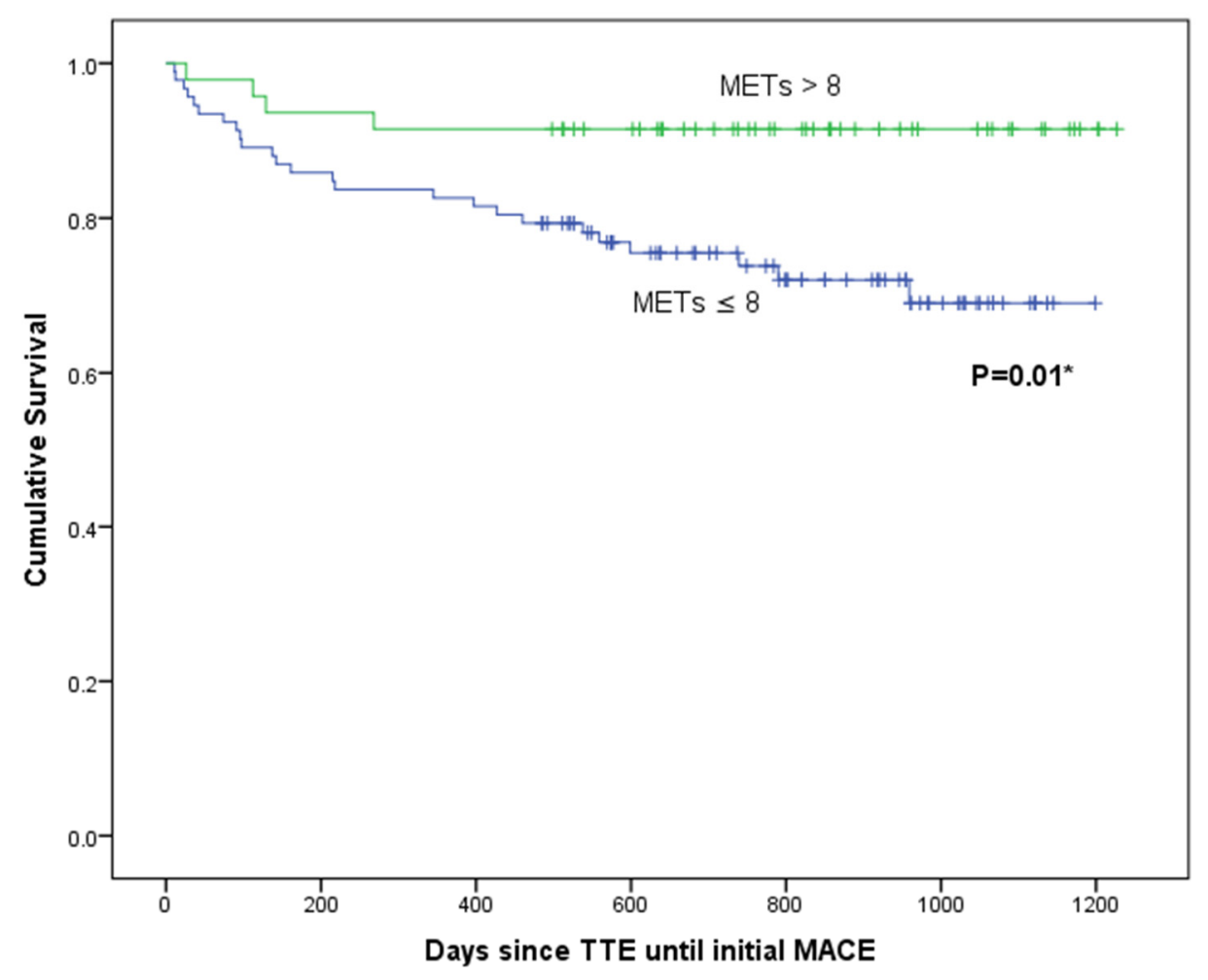

Figure 1. Kaplan-Meier estimates of exercise capacity from time of initial transthoracic echocardiogram to first major adverse cardiac event (MACE). METs, metabolic equivalents; TTE, transthoracic echocardiogram. ${ }^{*}$ Log-rank statistic.

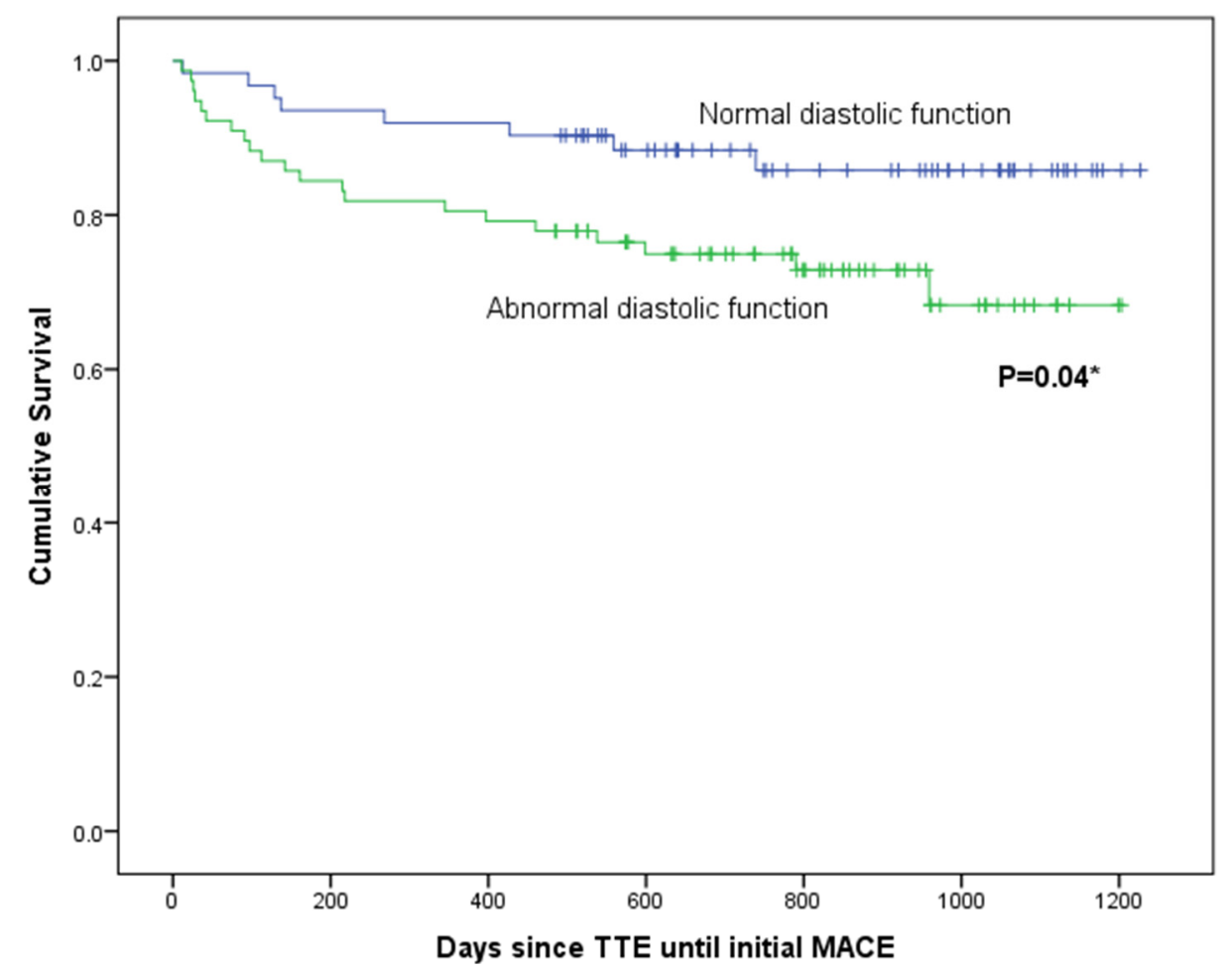

Figure 2. Kaplan-Meier estimates of left ventricular diastolic function (diastolic grade grouped as either normal or abnormal) from time of initial transthoracic echocardiogram to first major adverse cardiac event (MACE). TTE, transthoracic echocardiogram. ${ }^{*}$ Log-rank statistic. 
On univariate Cox regression analysis, METs $\leq 8(p=0.02)$ and abnormal diastolic function $(p=0.04)$ were associated with MACEs. On multivariate analysis (using abnormal diastolic function, METs, anterior infarction, and $\left.\mathrm{LAVI}_{\min }\right), \mathrm{METs} \leq 8$ was an independent predictor of MACEs (HR 3.4, 95\%CI 1.2-9.8; $p=0.02$ ).

\section{Discussion}

The main findings for our study are as follows: (1) Following first-ever STEMI, exercise capacity was reduced in approximately two-thirds of patients to $\leq 8 \mathrm{METs}$. (2) $\mathrm{LAVI}_{\min }$, anterior infarction, and abnormal diastolic function were predictors of METs achieved, independent of age and average E/e'. LV systolic function as determined by LVEF was not a determinant of METs. (3) In this STEMI cohort, a reduced number of METs $(<8)$ was an independent predictor of a composite of nonfatal and fatal MACEs.

Evaluation of diastolic function is complex and not determined by a single parameter. Current guidelines use a combination of several parameters to grade diastolic dysfunction [13]. Diastolic dysfunction is characterised by increased ventricular stiffness that can result in raised LV filling pressures, which are estimated noninvasively using $\mathrm{e}^{\prime}$ and $\mathrm{E} / \mathrm{e}^{\prime}$, respectively. Chronically elevated LV diastolic pressure in turn causes left atrial enlargement, and recent evidence suggests that $\mathrm{LAVI}_{\min }$ is often altered before the development of enlarged LAVI $\max$ [17]. Previous studies, albeit in a mixed group of patients with ACS, have shown that diastolic function defined by $\mathrm{e}^{\prime}$ and $\mathrm{E} / \mathrm{e}^{\prime}$ were predictors of exercise capacity, while LVEF was not $[1,6,8]$. However, in a multivariable model, which included overall diastolic function grade, $\mathrm{E} / \mathrm{e}^{\prime}$ was not an independent predictor, although in a recent study of chronic kidney disease patients without ACS, exercise E/e' was a predictor of exercise capacity [19]. Similarly, in a large study of a non-ACS population, abnormal diastolic function was an independent predictor of exercise capacity [7]. The strong association of diastolic impairment with exercise capacity can be explained pathophysiologically by the effect of impaired LV compliance and increased filling pressures, limiting the augmentation of stroke volume and cardiac output during exercise [20]. Additionally, both female gender and increasing age have been associated with diastolic impairment [20]. This may in part explain our findings of the association of age and female sex with reduced exercise capacity on univariate analysis and is consistent with a previous large $(n=2867)$ cross-sectional study of patients undergoing exercise echocardiography [7].

Although the prognostic significance of left atrial size and function has been demonstrated in heart failure and other conditions [21,22], data on left atrial size and exercise capacity is sparse. In our study, $\mathrm{LAVI}_{\min }$ was an independent predictor of exercise capacity. A recent study did demonstrate the effect of left atrial dilatation on exercise capacity [1]; however, to the best of our knowledge, no study has assessed $\mathrm{LAVI}_{\min }$ as a marker for ex-

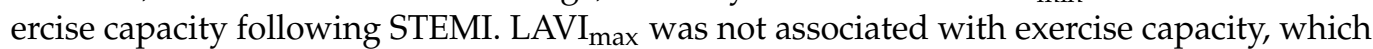
suggests that $\mathrm{LAVI}_{\min }$ may be a more sensitive marker of elevation of left ventricular filling pressures. Previous studies have demonstrated that $\mathrm{LAVI}_{\min }$ is more strongly associated with diastolic dysfunction and increased LV filling pressures than $\operatorname{LAVI}_{\max }[23,24]$, in part because enlargement of $\mathrm{LAVI}_{\min }$ would occur prior to an increase in $\mathrm{LAVI}_{\max }$. As reported recently, enlarged $\mathrm{LAVI}_{\min }$ with normal $\mathrm{LAVI}_{\max }$ has intermediate prognostic value, worse than patients with normal $\mathrm{LAVI}_{\min }$ and $\mathrm{LAVI}_{\max }$ but improved compared to those with both enlarged $\mathrm{LAVI}_{\min }$ and $\mathrm{LAVI}_{\max }$ in patients with myocardial infarction [17].

LV systolic function evaluated by LVEF is a predictor of mortality in STEMI patients [6]. A recent study evaluated LV function recovery following STEMI with serial LVEF measurements three months apart and demonstrated worse outcomes in those with persistently reduced LVEF at follow-up [25]. The utility of advanced echocardiography techniques including global longitudinal strain, a measure of LV contractility, has demonstrated prognostic value following STEMI [26]. However, strain measurements require two-dimensional data to be acquired at high frame rates with specialised software for their measurement, and thus they are not accessible in all centres. 
Exercise capacity has been previously correlated to early complete revascularisation in STEMI patients [27]; however, this was not a focus of the current study. Although in our study participants who had lower METs had a longer time to reperfusion, this failed to reach statistical significance, which suggests that ischaemia duration may have little effect on diastolic function, and is consistent with recently published data [28]. Protocolisation of STEMI management [5] and contemporary PCI have led to improvements in reperfusion times making LV systolic impairment less common. In our study, anterior infarction was independently associated with reduced exercise capacity, and this may be related to larger myocardial area at risk and consequent increase in diastolic dysfunction and elevated LV filling pressures [28].

Our study showed reduced exercise capacity to be an independent predictor of MACEs. This is consistent with other studies where the number of METs achieved was an independent predictor of cardiac morbidity and mortality in various clinical settings $[3,10,12]$, including those with recent AMI or after PCI [10], and in STEMI patients [2,11]. However, although diastolic dysfunction was significantly associated with MACEs, this was not an independent predictor in a multivariable model. This may be explained by the relatively small sample size of our study and the absence of subjects with grade 3 diastolic dysfunction (restrictive filling) in our cohort. Restrictive filling pattern has previously been shown to be an independent predictor of cardiac and all-cause mortality in an individual patient meta-analysis [29]. Naqvi et al. [30] demonstrated in patients with first-ever STEMI treated with primary PCI that E/ $\mathrm{e}^{\prime}$ was an independent predictor of in-hospital cardiac events in the short term and superior to all other parameters of LV diastolic and systolic function. However, mean E/ $\mathrm{e}^{\prime}$ was higher in their patient group when compared to our study population, suggesting more advanced diastolic dysfunction. Additionally, our follow-up duration was much longer, resulting in differing durations of medical treatments.

This study has some limitations. Firstly, this was a single-centre retrospective study with a relatively small number of patients and low event rates. Nonetheless, our results are novel and clinically important as a 'proof of concept study' and merit further investigation with larger studies. Secondly, peak troponin as a biochemical marker of infarct size was not assessed as the pathology testing at our hospital capped measurement of high-sensitive troponin I at 40,000 ng/L, preventing assessment of peak levels. Thirdly, details on preexisting diastolic dysfunction are lacking to determine whether diastolic dysfunction was present prior to STEMI or developed after STEMI. However, determining pre-existing diastolic function would not be possible given this was a cohort of first-ever STEMI of which the timing is unpredictable. We also did not perform analysis of patient medications given the relatively high use of appropriate therapy. Fourthly, this was a retrospective study, and hence advanced echocardiographic measurements such as strain analysis could not be evaluated. Finally, $<10 \%$ of our STEMI study population was female, which is lower compared to Australian registry data (25\% female) [31] and thus not generalisable to females. This may reflect a degree of selection bias in our study (i.e., patients who survived STEMI, had a TTE, attended cardiac rehabilitation, and completed ETT).

\section{Conclusions}

In patients who underwent ETT following first-ever STEMI, $\mathrm{LAVI}_{\mathrm{min}}$, anterior infarction, and abnormal diastolic function were independent predictors of exercise capacity and superior to clinical variables and other echocardiographic parameters including LVEF, demonstrating the impact of abnormal diastolic function on exercise capacity in STEMI patients. Furthermore, reduced exercise capacity was an independent predictor of MACEs, demonstrating the prognostic value of this relatively easy to obtain parameter in STEMI patients undergoing cardiac rehabilitation. Although our data require confirmation in larger prospective studies, the results highlight important implications for monitoring and surveillance of STEMI patients with diastolic dysfunction distinct from those with LV systolic impairment. 
Author Contributions: Conceptualization, H.K., M.A. and L.T.; data curation, H.K. and A.F.; formal analysis, H.K.; investigation, H.K., A.F., P.B. and R.Z.; methodology, H.K., M.A. and L.T.; resources, P.B. and R.Z.; supervision, L.T.; validation, M.A. and L.T.; visualization, H.K.; writing-original draft, H.K.; writing-review and editing, H.K., A.F., P.B., R.Z., M.A. and L.T. All authors have read and agreed to the published version of the manuscript.

Funding: This research received no external funding.

Institutional Review Board Statement: The study was conducted according to the guidelines of the Declaration of Helsinki and approved by the Western Sydney Local Health District (WSLHD) Human Research Ethics Committee (AU RED LNR/17/WMEAD/192).

Informed Consent Statement: Patient consent was waived due to the retrospective nature of this study and following institutional ethics board review.

Data Availability Statement: In line with the requirements of the ethics committee who approved this research, requests for access to data are to be made in writing to the corresponding author. Only deidentified participant data can be made available to suitably qualified researchers on reasonable request.

Acknowledgments: Harry Klimis is supported by a Royal Australian College of Physicians (RACP) Fellows Research Entry Scholarship, an Australian Government Research Training Program scholarship, and a University of Sydney Supplementary scholarship. Liza Thomas has not received any funding to perform this study.

Conflicts of Interest: The authors declare no conflict of interest.

\begin{tabular}{|c|c|}
\hline \multicolumn{2}{|c|}{ Abbreviations } \\
\hline ACE & Angiotensin-converting enzyme \\
\hline ACS & Acute coronary syndrome \\
\hline AMI & Acute myocardial infarction \\
\hline ECG & Electrocardiogram \\
\hline EDV & End-diastolic volume \\
\hline ESV & End-systolic volume \\
\hline ETT & Exercise treadmill testing \\
\hline $\mathrm{LAVI}_{\max }$ & Maximum left atrial indexed volume \\
\hline $\mathrm{LAVI}_{\min }$ & Minimum left atrial indexed volume \\
\hline LV & Left ventricular \\
\hline LVEF & Left ventricular ejection fraction \\
\hline MACEs & Major adverse cardiac events \\
\hline METs & Metabolic equivalents \\
\hline NSTEMI & Non-ST-elevation myocardial infarction \\
\hline PCI & Percutaneous coronary intervention \\
\hline STEMI & ST-elevation myocardial infarction \\
\hline TTE & Transthoracic echocardiogram \\
\hline
\end{tabular}

\section{References}

1. Tashiro, H.; Tanaka, A.; Ishii, H.; Motomura, N.; Arai, K.; Adachi, T.; Okajima, T.; Iwakawa, N.; Kojima, H.; Mitsuda, T.; et al. Reduced exercise capacity and clinical outcomes following acute myocardial infarction. Heart Vessel. 2020, 35, 1044-1050. [CrossRef] [PubMed]

2. Valeur, N.; Clemmensen, P.; Saunamäki, K.; Grande, P. The prognostic value of pre-discharge exercise testing after myocardial infarction treated with either primary PCI or fibrinolysis: A DANAMI-2 sub-study. Eur. Heart J. 2004, 26, 119-127. [CrossRef] [PubMed]

3. Peterson, P.N.; Magid, D.J.; Ross, C.; Ho, P.M.; Rumsfeld, J.S.; Lauer, M.; Lyons, E.E.; Smith, S.S.; Masoudi, F.A. Association of Exercise Capacity on Treadmill with Future Cardiac Events in Patients Referred for Exercise Testing. Arch. Intern. Med. 2008, 168, 174-179. [CrossRef] [PubMed]

4. Lawler, P.R.; Filion, K.B.; Eisenberg, M.J. Efficacy of exercise-based cardiac rehabilitation post-myocardial infarction: A systematic review and meta-analysis of randomized controlled trials. Am. Heart J. 2011, 162, 571-584.e2. [CrossRef] [PubMed] 
5. Chew, D.; Scott, I.; Cullen, L.; French, J.K.; Briffa, T.G.; Tideman, P.A.; Woodruffe, S.; Kerr, A.; Branagan, M.; Aylward, P. National Heart Foundation of Australia \& Cardiac Society of Australia and New Zealand: Australian Clinical Guidelines for the Management of Acute Coronary Syndromes 2016. Heart Lung Circ. 2016, 25, 895-951.

6. Dekleva, M.N.; Mazic, S.D.; Suzic-Lazic, J.M.; Marković-Nikolić, N.S.; Beleslin, B.D.; Stevanović, A.M.; Djelic, M.N.; Arandjelović, A.M. Left ventricular diastolic performance at rest is essential for exercise capacity in patients with noncomplicated myocardial infarction. Heart Lung 2014, 43, 500-505. [CrossRef]

7. Grewal, J.; McCully, R.B.; Kane, G.C.; Lam, C.; Pellikka, P.A. Left ventricular function and exercise capacity. JAMA 2009, 301, 286-294. [CrossRef]

8. Fontes-Carvalho, R.; Sampaio, F.; Teixeira, M.; Rocha-Gonçalves, F.; Gama, V.; Azevedo, A.; Leite-Moreira, A. Left Ventricular Diastolic Dysfunction and E/E' Ratio as the Strongest Echocardiographic Predictors of Reduced Exercise Capacity after Acute Myocardial Infarction. Clin. Cardiol. 2015, 38, 222-229. [CrossRef]

9. Miyashita, T.; Okano, Y.; Takaki, H.; Satoh, T.; Kobayashi, Y.; Goto, Y. Relation between exercise capacity and left ventricular systolic versus diastolic function during exercise in patients after myocardial infarction. Coron. Artery Dis. 2001, 12, $217-225$. [CrossRef]

10. Yu, C.-M.; Lau, C.-P.; Cheung, B.M.-Y.; Fong, Y.-M.; Ho, Y.-Y.; Lam, K.-B.; Li, L.S. Clinical predictors of morbidity and mortality in patients with myocardial infarction or revascularization who underwent cardiac rehabilitation, and importance of diabetes mellitus and exercise capacity. Am. J. Cardiol. 2000, 85, 344-349. [CrossRef]

11. Dutcher, J.R.; Kahn, J.; Grines, C.; Franklin, B. Comparison of Left Ventricular Ejection Fraction and Exercise Capacity as Predictors of Two- and Five-Year Mortality following Acute Myocardial Infarction. Am. J. Cardiol. 2007, 99, 436-441. [CrossRef] [PubMed]

12. Myers, J.; Prakash, M.; Froelicher, V.; Do, D.; Partington, S.; Atwood, J.E. Exercise Capacity and Mortality among Men Referred for Exercise Testing. N. Engl. J. Med. 2002, 346, 793-801. [CrossRef] [PubMed]

13. Nagueh, S.F.; Smiseth, O.A.; Appleton, C.P.; Byrd, B.F., 3rd; Dokainish, H.; Edvardsen, T.; Flachskampf, F.A.; Gillebert, T.C.; Klein, A.L.; Lancellotti, P.; et al. Recommendations for the Evaluation of Left Ventricular Diastolic Function by Echocardiography: An Update from the American Society of Echocardiography and the European Association of Cardiovascular Imaging. Eur. Heart J. Cardiovasc. Imaging 2016, 17, 1321-1360. [CrossRef] [PubMed]

14. Kanthan, A.; Tan, T.C.; Zecchin, R.P.; Denniss, A.R. Early exercise stress testing is safe after primary percutaneous coronary intervention. Eur. Heart J. Acute Cardiovasc. Care 2012, 1, 153-157. [CrossRef] [PubMed]

15. Galderisi, M.; Cosyns, B.; Edvardsen, T.; Cardim, N.; Delgado, V.; Di Salvo, G.; Donal, E.; Sade, L.E.; Ernande, L.; Garbi, M.; et al. Standardization of adult transthoracic echocardiography reporting in agreement with recent chamber quantification, diastolic function, and heart valve disease recommendations: An expert consensus document of the European Association of Cardiovascular Imaging. Eur. Heart J. Cardiovasc. Imaging 2017, 18, 1301-1310. [PubMed]

16. Wu, V.C.; Takeuchi, M.; Kuwaki, H.; Iwataki, M.; Nagata, Y.; Otani, K.; Haruki, N.; Yoshitani, H.; Tamura, M.; Abe, H.; et al. Prognostic value of LA volumes assessed by transthoracic 3D echocardiography: Comparison with 2D echocardiography. JACC Cardiovasc. Imaging 2013, 6, 1025-1235. [CrossRef] [PubMed]

17. Prasad, S.B.; Guppy-Coles, K.; Stanton, T.; Armstrong, J.; Krishnaswamy, R.; Whalley, G.; Atherton, J.J.; Thomas, L. Relation of Left Atrial Volumes in Patients with Myocardial Infarction to Left Ventricular Filling Pressures and Outcomes. Am. J. Cardiol. 2019, 124, 325-333. [CrossRef]

18. Lang, R.M.; Badano, L.P.; Mor-Avi, V.; Afilalo, J.; Armstrong, A.; Ernande, L.; Flachskampf, F.A.; Foster, E.; Goldstein, S.A.; Kuznetsova, T.; et al. Recommendations for cardiac chamber quantification by echocardiography in adults: An update from the American Society of Echocardiography and the European Association of Cardiovascular Imaging. Eur. Heart J. Cardiovasc. Imaging 2015, 16, 233-270. [CrossRef] [PubMed]

19. Gan, G.C.; Kadappu, K.K.; Bhat, A.; Fernandez, F.; Eshoo, S.; Thomas, L. Exercise E/e' Is a Determinant of Exercise Capacity and Adverse Cardiovascular Outcomes in Chronic Kidney Disease. JACC Cardiovasc. Imaging 2020, 13, 2485-2494. [CrossRef]

20. Leite-Moreira, A.F. Current perspectives in diastolic dysfunction and diastolic heart failure. Heart 2006, 92, 712-718. [CrossRef]

21. Pellicori, P.; Zhang, J.; Lukaschuk, E.; Joseph, A.C.; Bourantas, C.V.; Loh, H.; Bragadeesh, T.; Clark, A.L.; Cleland, J.G. Left atrial function measured by cardiac magnetic resonance imaging in patients with heart failure: Clinical associations and prognostic value. Eur. Heart J. 2015, 36, 733-742. [CrossRef]

22. Vieira, M.J.; Teixeira, R.; Goncalves, L.; Gersh, B.J. Left Atrial Mechanics: Echocardiographic Assessment and Clinical Implications. J. Am. Soc. Echocardiogr. 2014, 27, 463-478. [CrossRef] [PubMed]

23. Russo, C.; Jin, Z.; Homma, S.; Rundek, T.; Elkind, M.S.; Sacco, R.L.; Di Tullio, M.R. Left atrial minimum volume and reservoir function as correlates of left ventricular diastolic function: Impact of left ventricular systolic function. Heart 2012, 98, 813-820. [CrossRef] [PubMed]

24. Caselli, S.; Canali, E.; Foschi, M.L.; Santini, D.; Di Angelantonio, E.; Pandian, N.G.; De Castro, S. Long-term prognostic significance of three-dimensional echocardiographic parameters of the left ventricle and left atrium. Eur. J. Echocardiogr. 2010, 11, 250-256. [CrossRef] [PubMed]

25. Dauw, J.; Martens, P.; Deferm, S.; Bertrand, P.; Nijst, P.; Hermans, L.; Bergh, M.V.D.; Housen, I.; Hijjit, A.; Warnants, M.; et al. Left ventricular function recovery after ST-elevation myocardial infarction: Correlates and outcomes. Clin. Res. Cardiol. 2021, 110, 1504-1515. [CrossRef] [PubMed] 
26. Iwahashi, N.; Kirigaya, J.; Gohbara, M.; Abe, T.; Horii, M.; Hanajima, Y.; Toya, N.; Takahashi, H.; Minamimoto, Y.; Kimura, Y.; et al. Global Strain Measured by Three-Dimensional Speckle Tracking Echocardiography Is a Useful Predictor for 10-Year Prognosis after a First ST-Elevation Acute Myocardial Infarction. Circ. J. 2021, 85, 1735-1743. [CrossRef]

27. Zhao, W.; Bai, J.; Zhang, F.; Guo, L.; Gao, W. Impact of completeness of revascularization by coronary intervention on exercise capacity early after acute ST-elevation myocardial infarction. J. Cardiothorac. Surg. 2014, 9, 50. [CrossRef]

28. Søholm, H.; Lønborg, J.; Andersen, M.J.; Vejlstrup, N.; Engstrøm, T.; Hassager, C.; Møller, J.E. Association diastolic function by echo and infarct size by magnetic resonance imaging after STEMI. Scand. Cardiovasc. J. 2016, 50, 172-179. [CrossRef]

29. Hillis, G.; Meta-Analysis Research Group in Echocardiography (MeRGE) AMI Collaborators. Independent prognostic importance of a restrictive left ventricular filling pattern after myocardial infarction: An individual patient meta-analysis: Meta-Analysis Research Group in Echocardiography acute myocardial infarction. Circulation 2008, 117, 2591-2598.

30. Naqvi, T.Z.; Padmanabhan, S.; Rafii, F.; Hyuhn, H.K.; Mirocha, J. Comparison of usefulness of left ventricular diastolic versus systolic function as a predictor of outcome following primary percutaneous coronary angioplasty for acute myocardial infarction. Am. J. Cardiol. 2006, 97, 160-166. [CrossRef]

31. Khan, E.; Brieger, D.; Amerena, J.; Atherton, J.J.; Chew, D.P.; Farshid, A.; Ilton, M.; Juergens, C.P.; Kangaharan, N.; Rajaratnam, R.; et al. Differences in management and outcomes for men and women with ST-elevation myocardial infarction. Med. J. Aust. 2018, 209, 118-123. [CrossRef] [PubMed] 